\title{
ENERGI KONSERVASI PADA POMPA SENTRIFUGAL DENGAN TORQUE FLOW IMPELLER SEMI OPEN DAN CLOSED PADA PENGATURAN KAPASITAS
}

\author{
Indra Herlamba Siregar \\ Jurusan Teknik Mesin, Fakultas Teknik, Universitas Negeri Surabaya \\ indrasiregar@unesa.ac.id
}

\begin{abstract}
Abstrak - Pompa adalah rotating equipment yang paling banyak digunakan baik disektor domestik maupun industry dengan kontribusi pemakaian energi listrik dunia sekitar $3 \%$, selain itu ukuran pompa yang tersedia dengan kebutuhan banyak yang tidak sesuai sehingga perlu mengatur kapasitasnya. Pada artikel ini ada dua metoda pengaturan kapasitas yang diujikan yaitu dengan bukaan katup dan variable speed drive pada pompa sentrifugal torque flow impeller semi open dan closed dengan jumlah bilah 7, 8 dan 9. Hasil memaparkan bahwa pada metoda bukaan katup jumlah bilah berpengaruh terhadap konsumsi daya listrik pompa walaupun tidak cukup signifikan sedangkan pada metoda variable speed drive jumlah bilah tidak berpengaruh. Namun konsumsi daya listrik impeller closed lebih rendah daripada impeller semi open pada metoda bukaan katup dan tidak ada perbedaan yang signifikan pada metoda variable speed drive. Metoda pengaturan kapasitas dengan variable speed drive mengkonsumsi daya listrik yang lebih rendah daripada metoda bukaan katup semakin besar pengaturan aliran pompa dari kondisi awal semakin besar penghematan yang diperoleh dengan metoda variable speed drive daripada metoda bukaan katup.
\end{abstract}

Kata Kunci- torque flow impeller, jumlah bilah, variable speed drive, bukaan katup.

\begin{abstract}
Pumps are the most widely used rotating equipment in both the domestic and industrial sectors with a contribution of around 3\% of the world's electrical energy usage, in addition to the size of pumps available with many incompatible requirements, it is necessary to regulate their capacity. In this article, there are two capacity setting methods tested, namely valve opening and variable speed drive on semi open and closed centrifugal pump torque flow impeller with blades of 7,8 and 9. The results explain that in valve opening method the number of blades affects the power consumption pump electricity, although not significant enough, while the variable speed drive method, the number of blades has no effect. However, the power consumption of the impeller closed is lower than the semi open impeller in the valve opening method and there is no significant difference in the variable speed drive method. The capacity setting method with a variable speed drive consumes less electric power than the valve opening method, if the flow of pump more decrease from the initial condition the greater the savings obtained with the variable speed drive method than the valve opening method.
\end{abstract}

Key Words - torque flow impeller, blade number, variable speed drive, valve opening.

\section{Pendahuluan}

Pompa digunakan untuk meningkatkan tekanan fluida menggunakan input daya dari motor atau mesin. Perawatan pompa komersial tersedia dalam berbagai ukuran, desain, dan kapasitas. Kinerja setiap pompa ditandai dengan peningkatan energi fluida atau head pompa, daya yang dibutuhkan untuk mengoperasikan pompa, dan efisiensi pompa. Ketiga parameter ini bervariasi sesuai dengan laju aliran fluida. Pengujian pompa akan mengungkapkan bagaimana head pompa, daya, dan efisiensi berbeda laju aliran. Hasil tes biasanya digunakan untuk menggambar kurva kinerja pompa, kinerja pompa sentrifugal dipengaruhi oleh desain bilah pompa, jumlah bilah dan bentuk geometris bilah [1].
Peningkatan jumlah bilah ternyata juga meningkatkan kinerja pompa sentrifugal baik dengan impeller konvensional [2-5] maupun impeller torque flow [6-7]. Pompa sentrifugal telah digunakan dalam aplikasi industri dan domestik, seperti pembangkit listrik tenaga uap, pabrik pasokan air, pembuangan limbah, drainase atau irigasi, kilang minyak, layanan tenaga hidrolik dan kapal. Fluida masuk ke pompa akibat rotasi impeller yang membuat efek isap lalu fluida mengambil energi dari impeller dalam bentuk energi dan tekanan kinetik [1]. Sistem pompa menyumbang hampir $2 \mathrm{s.d}$ $3 \%$ dari kebutuhan energi listrik dunia dengan kisaran 80 s.d $90 \%$ dari porsi tersebut digunakan oleh motor listrik sebagai pengerak pompa [8]. Seiring meningkatnya biaya energi, pabrik pemrosesan meningkatkan fokus mereka pada jumlah energi yang dikonsumsi oleh rotating equipment. Selain itu 
ukuran pompa yang tidak benar atau berkinerja buruk berdampak terhadap biaya yang tidak perlu [9], hal ini disebabkan hasil perhitungan dari rencana layout kebutuhan pompa kadang tidak tersedia atau perkiraan dari factor keamanan yang overestimated, untuk itu ada beberapa metoda pengaturan kapasitas pompa yaitu pengaturan dengan perubahan posisi katup, mengecilkan diameter impeller, mengatur bypass dan penggunaan variable speed drive [9]. Jenis impeller juga berpengaruh terhadap kinerja pompa sentrifugal dengan penerapan tergantung kondisi fluida yang dipompakan, secara umum impeller pompa sentrifugal terbagi menjadi tiga yaitu open, semi dan closed impeller, dimana closed impeller ditinjau dari effisiensinya memiliki nilai tertinggi dibandingkan jenis impeller yang lain [10]. Berdasarkan uraian diatas artikel ini akan membahas konservasi energi dengan metoda pengaturan kapasitas pada pompa sentrifugal dengan torque flow impeller jenis semi dan closed impeller.

\section{Metode}

Pada penelitian yang dilakukan sekarang adalah pengujian pompa sentrifugal di test bed dengan susunan rangkaian alat dapat dilihat pada gambar 1, dengan torque flow impeller jenis semi dan closed dengan jumlah sudu 7,8 dan 9 lihat gambar 2 . Instrumen yang diguakan untuk mengukur putaran pompa adalah non contact tachometer Lutron DT 1236 L dengan rentang 5-99,999 rmp dengan resolusi 0,5 rpm. Sedangkan untuk mengukur konsumsi listrik pompa menggunakan Clampmeter Krisbow KW 06-286 dengan rentang pembacaan arus 2-400 A dan tegangan 2, 20, 200 dan $600 \mathrm{~V}$.

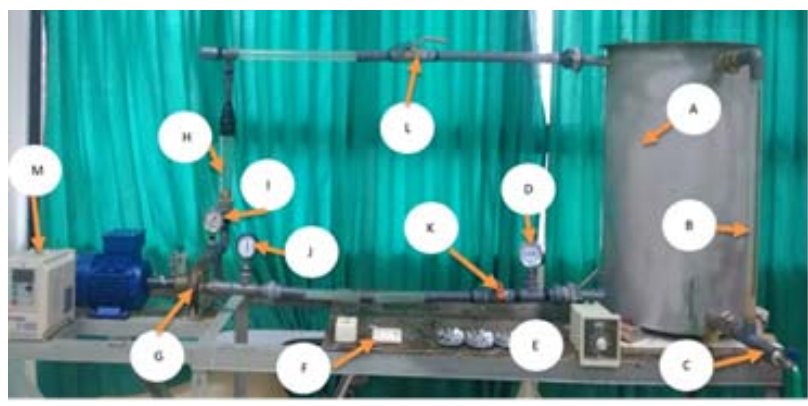

Gambar 1. Rangkaian peralatan Uji

Keterangan :

a Tabung reservoir $\mathrm{h}$ Flow meter

b Pengukur ketinggian air i Manometer dalam reservoir

c Kran penguras air dalam j Manometer reservoir

d Thermometer

e Thermocontrol

f Saklar

g Rumah pompa sentrifugal
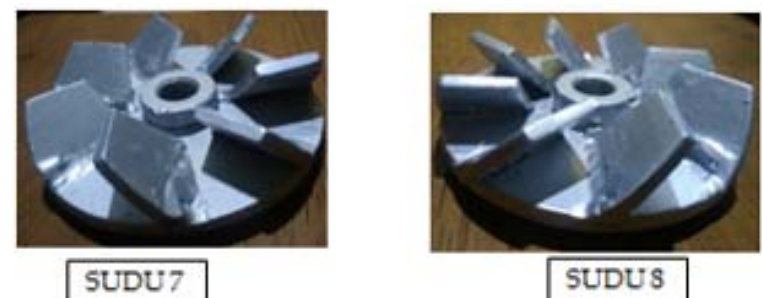

SUDU

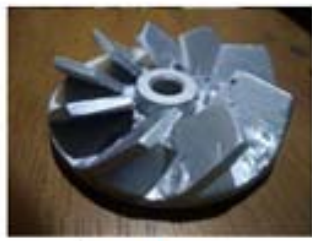

SUDU 9

(a)

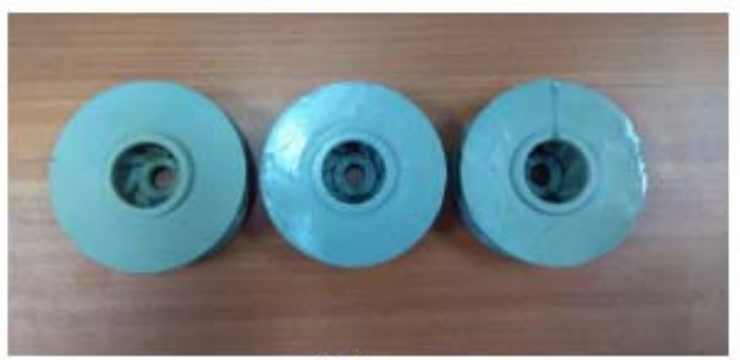

(b)

Gambar 2. Torque Flow Impeller (a) Semi Open (b) Closed

Aliran fuida diukur dengan Rotameter dengan maksimum mengukur aliran sebesar 60 liter per menit. Adapun konsumsi daya listrik dihitung dengan persamaan berikut ini :

$$
P=\sqrt{ } 3 \mathrm{~V} . \mathrm{I}
$$

\section{HASIL DAN DISKUSI}

Pengaruh jumlah bilah terhadap konsumsi daya listrik pompa sentrifugal torque flow impeller semi open maupun closed pada pengaturan katup dipaparkan pada gambar 3 dan 4. Jumlah bilah pada jenis impeller semi open memiliki pengaruh cukup signifikan terhadap konsumsi daya listrik dimana semakin besar jumlah bilah konsumsi daya listriknya semakin kecil. Hal ini dikarenakan konstruksi semi open hanya tertutup pada salah satu sisinya sedangkan sisi lainnya terbuka (lihat gambar 2a) sehingga bertambahnya jumlah bilah maka jarak antar bilah lebih kecil, hal ini mengakibatkan vortisiti aliran diujung bilah pada sisi yang terbuka semakin kecil akibatnya tahanan fluida juga semakin kecil. Sehingga untuk kapasitas fluida yang dipompakan sama maka daya yang dibutuhkan oleh pompa dengan jumlah bilah yang lebih banyak lebih kecil daripada jumlah bilah yang lebih kecil. 


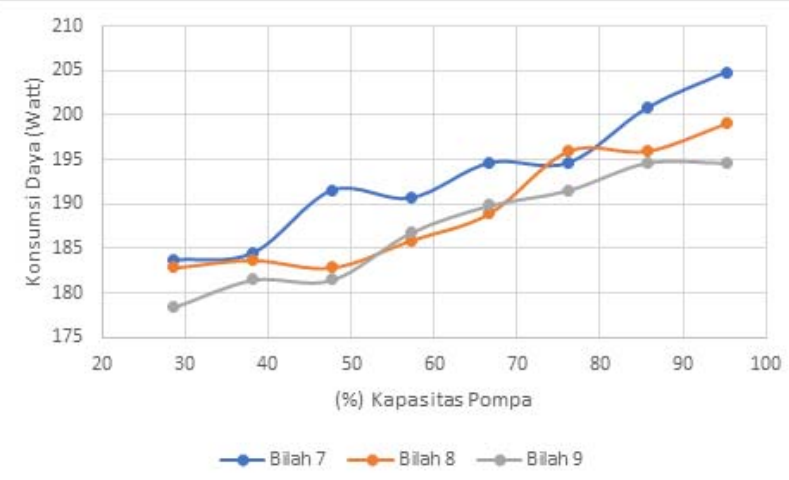

Gambar 3. Konsumsi daya pompa sentrifugal dengan torque flow impeller semi open dengan mengatur kapasitas pompa dengan bukaan katup

Namun pada jenis impeller jenis closed pengaruh jumlah bilah tidak signifikan dikarenakan konstruksinya tertutup di dua sisinya ( lihat gambar 2b). Hal ini menyebabkan fluida yang melintasi celah antar bilah memiliki alur dan timbulnya vortisiti yang muncul diujung bilah pada jenis semi open bisa diredam sehingga perbedaan jumlah bilah tidak cukup signifikan terhadap konsumsi daya listrik (lihat gambar 4).

Gambar 5 memperlihatkan pengaruh pengaturan kapasitas aliran pompa sentrifugal torque flow impeller semi open dengan variable speed drive terhadap konsumsi daya listrik pompa, terlihat bahwa jumlah bilah tidak memiliki pengaruh yang cukup signifikan.

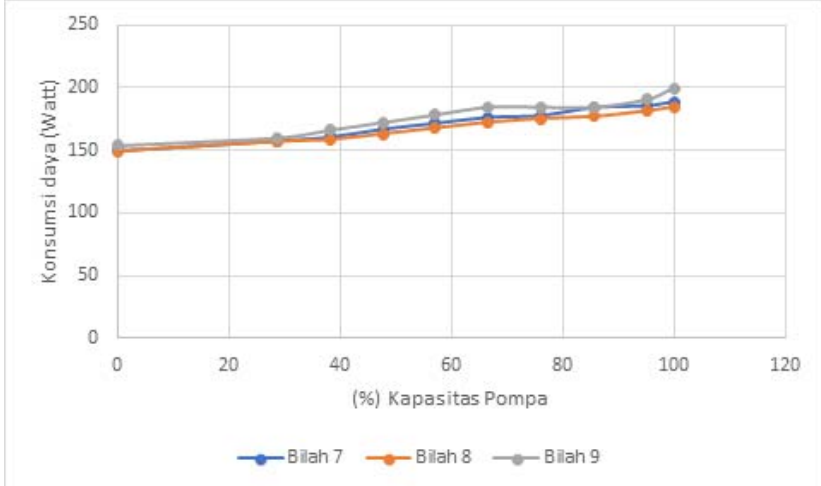

Gambar 4. Konsumsi daya pompa sentrifugal dengan torque flow impeller closed dengan mengatur kapasitas pompa dengan bukaan katup

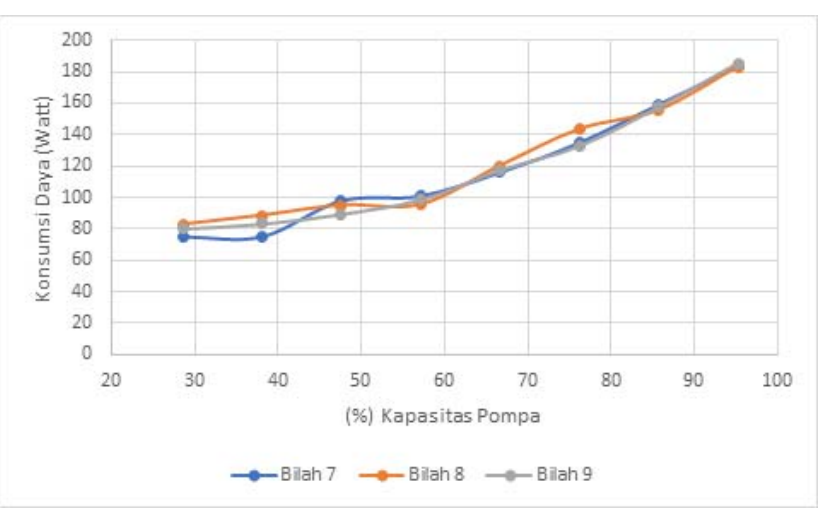

Gambar 5. Konsumsi daya pompa sentrifugal dengan torque flow impeller semi open dengan mengatur kapasitas pompa dengan variable speed drive

Sedangkan untuk pompa sentrifugal torque flow closed impeller juga memperlihatkan fenomena yang sama dengan jenis semi open dimana jumlah bilah tidak berpengaruh terhadap konsumsi daya listrik pompa ( lihat Gambar 6).

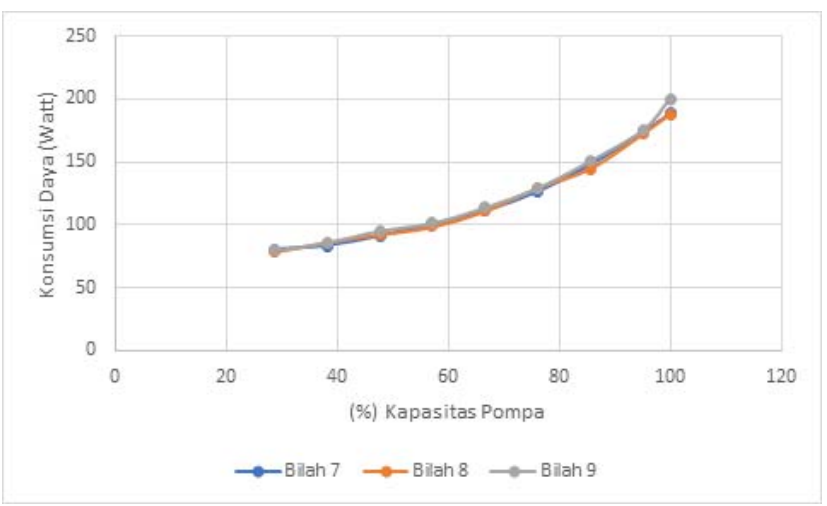

Gambar 6. Konsumsi daya pompa sentrifugal dengan torque flow impeller closed dengan mengatur kapasitas pompa dengan variable speed drive.

Dari paparan sebelumnya terlihat bilah 9 menunjukkan konsumsi daya listrik terkecil untuk impeller jenis semi open pada pengaturan kapasitas dengan pengaturan bukaan katup sedangkan pada pengaturan kapasitas dengan variable speed drive jumlah bilah tidak menunjukkan pengaruh yang cukup signifikan terhadap konsumsi daya listrik. Untuk impeller jenis closed terlihat baik pada pengaturan kapasitas dengan pengaturan katup maupun dengan variable speed drive jumlah bilah tidak berpengaruh terhadap konsumsi daya listrik pompa, sehingga untuk paparan selanjutnya penulis memaparkan gambar dengan jumlah bilah 9 . 


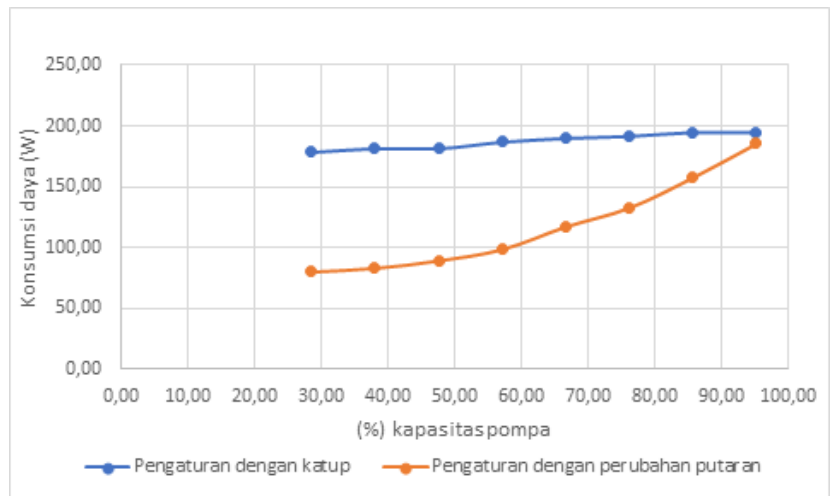

Gambar 7. Komparasi konsumsi daya pompa sentrifugal dengan torque flow impeller semi open antara mengatur kapasitas pompa dengan bukaan katup dan variable speed drive pada bilah 9

Gambar 7 memperlihatkan bahwa untuk impeller semi open metoda pengaturan kapasitas aliran pompa dengan menggunakan variable speed drive lebih menghemat penggunaan daya listrik. Jika pengaturan aliran yang dipompakan sebesar $76 \%$ dari kapasitas awal pompa pada bukaan penuh katup maka penghematan yang diperoleh dengan metoda variable speed drive sebesar 30,65\% daripada dengan metoda bukaan katup dan 50,63\% jika pengaturan kapasitas sebesar 47,62\% dari kapasitas awal lihat tabel 1.

Tabel 1. Perbandingan konsumsi daya pada impeller semi open jumlah bilah 9

\begin{tabular}{|r|r|r|c|}
\hline $\begin{array}{c}\text { (\%) } \\
\text { Kapasitas }\end{array}$ & $\begin{array}{c}\text { Pengaturan dengan } \\
\text { bukaan katup (W) }\end{array}$ & $\begin{array}{c}\text { Pengaturan dengan } \\
\text { variable speed drive (W) }\end{array}$ & \multicolumn{1}{c|}{$(\%)$} \\
\hline 95,24 & 194,67 & 185,40 & $-4,76$ \\
\hline 85,71 & 194,67 & 157,59 & $-19,05$ \\
\hline 76,19 & 191,58 & 132,87 & $-30,65$ \\
\hline 66,67 & 189,86 & 117,42 & $-38,16$ \\
\hline 57,14 & 186,80 & 98,88 & $-47,07$ \\
\hline 47,62 & 181,49 & 89,61 & $-50,63$ \\
\hline 38,10 & 181,49 & 83,43 & $-54,03$ \\
\hline 28,57 & 178,42 & 80,34 & $-54,97$ \\
\hline
\end{tabular}

Sedangkan untuk impeller closed metoda pengaturan kapasitas aliran pompa dengan menggunakan variable speed drive lebih menghemat penggunaan daya listrik sebesar $30 \%$, jika pengaturan aliran yang dipompakan sebesar $76 \%$ dari kapasitas awal pompa pada bukaan penuh katup dan 44,64\% pada kapasitas 47,62\% dari kapasitas awal lihat tabel 2 .

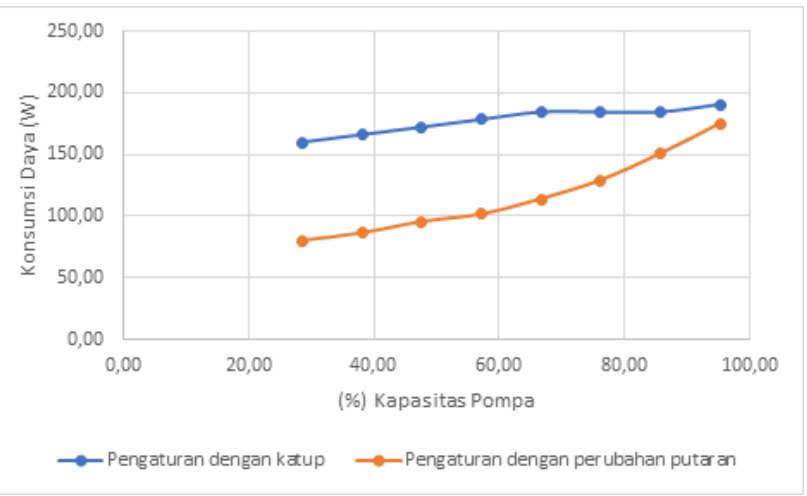

Gambar 8. Komparasi konsumsi daya pompa sentrifugal dengan torque flow impeller closed antara mengatur kapasitas pompa dengan bukaan katup dan variable speed drive pada bilah 9

Tabel 2. Perbandingan konsumsi daya pada impeller closed jumlah bilah 9

\begin{tabular}{|r|r|r|c|}
\hline $\begin{array}{c}\text { (\%) } \\
\text { Kapasitas }\end{array}$ & $\begin{array}{r}\text { Pengaturan dengan } \\
\text { bukaan katup (W) }\end{array}$ & $\begin{array}{c}\text { Pengaturan dengan } \\
\text { variable speed drive (W) }\end{array}$ & \begin{tabular}{c} 
(\%) \\
\hline 95,24
\end{tabular}$\quad 190,72$ \\
184,57 & 175,34 & $-8,06$ \\
\hline 85,71 & 184,57 & 129,20 & $-18,33$ \\
\hline 76,19 & 184,57 & 113,82 & $-38,00$ \\
\hline 66,67 & 178,42 & 101,51 & $-43,10$ \\
\hline 57,14 & 172,26 & 95,36 & $-44,64$ \\
\hline 47,62 & 166,11 & 86,13 & $-48,15$ \\
\hline 38,10 & 159,96 & 79,98 & $-50,00$ \\
\hline 28,57 & & & \\
\hline
\end{tabular}

Pada metoda pengaturan kapasitas dengan bukaan katup pompa sentrifugal dengan impeller closed lebih kecil konsumsi daya listriknya daripada impeller semi open walaupun tidak cukup signifikan (lihat gambar 9).

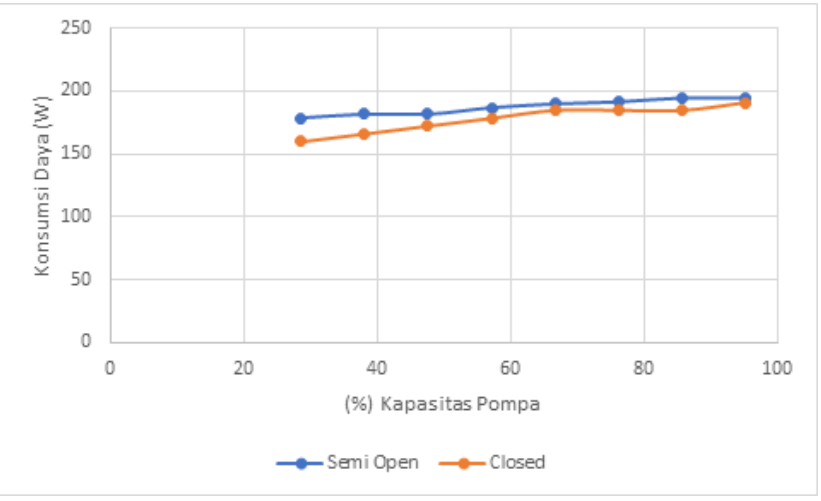

Gambar 9. Komparasi konsumsi daya pompa sentrifugal dengan torque flow impeller semi open dan closed dengan pengaturan kapasitas pompa dengan bukaan katup pada bilah 9

Sedangkan pengaturan kapasitas dengan metoda variable speed drive, daya listrik yang dikonsumsi pompa sentrifugal 
dengan impeller semi open dan closed tidak ada perbedaan yang signifikan (lihat gambar 10).

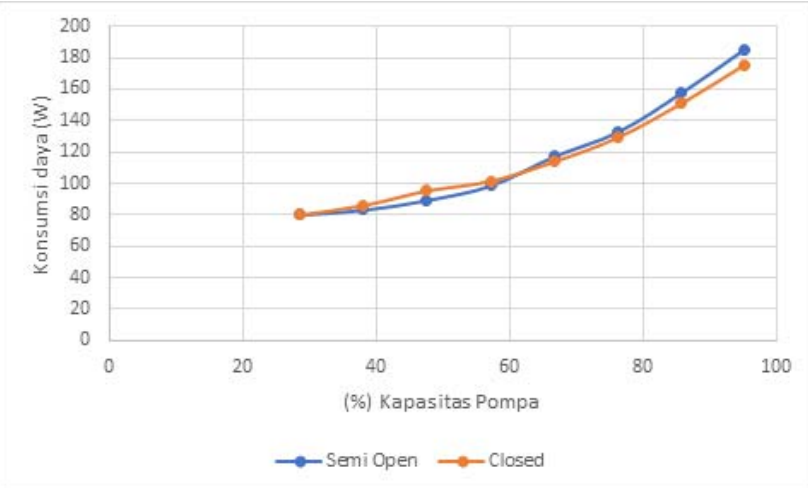

Gambar 10. Komparasi konsumsi daya pompa sentrifugal dengan torque flow impeller semi open dan closed dengan pengaturan kapasitas pompa dengan variable speed drive pada bilah 9

\section{KESIMPULAN}

Dari uraian diatas mengenai koservasi energi dari pompa sentrifugal torque impeller semi open dan closed dengan variasi jumlah bilah 7,8 dan 9 diperoleh beberapa kesimpulan:

1. Pada metoda pengaturan kapasitas aliran pompa dengan bukaan katup, jumlah bilah impeller berpengaruh terhadap konsumsi daya listrik untuk jenis impeller semi open dengan jumlah bilah 9 menunjukkan konsumsi daya listriknya sedangkan pada impeller closed jumlah bilah tidak berpengaruh terhadap konsumsi listrik pompa.

2. Sedangkan pada pengaturan kapasitas pompa dengan variable speed drive jumlah bilah baik impeller semi open dan closed tidak berpengaruh terhadap konsumsi listrik pompa.

3. Konsumsi daya listrik pada pengaturan kapasitas aliran pompa dengan metoda variable speed drive lebih hemat daripada dengan metoda bukaan katup.

\section{UCAPAN TERIMA KASIH}

Penulis mengucapkan terima kasih pada Universitas Negeri Surabaya yang membiayai penelitian ini melalui skim Penelitian Kebijakan Fakultas.

\section{REFERENSI}

[1] E. Korkmaz1, M. Gölcü2 and C. Kurbanoğlu, Effects of Blade Discharge Angle, Blade Number and Splitter Blade Length on Deep Well Pump Performance, Journal of Applied Fluid Mechanics, Vol. 10, No. 2, pp. 529-540, 2017.

[2] Elyamin, G. R. A., Bassily, M. A., Khalil, K. Y., Gomaa, M. S. (2019). Effect of impeller blades number on the performance of a centrifugal pump. Alexandria Engineering Journal, 58(1), 3948 .
[3] Sembada, S., Siregar, I.H. (2017) Pengaruh Jumlah Bilah Centrifugal Impeller Terhadap NPSH Pompa. Jurnal Teknik Mesin, 5(1), $101-110$.

[4] Musyafa, A. A., Siregar, I.H. (2015), Pengaruh Jumlah Sudu Sentrifugal Impeller Terhadap Kapasitas dan Efisiensi Pompa Sentrifugal. Jurnal Teknik Mesin, 3(3), 136 - 144.

[5] Nugroho, S., Juwana, W. E., Himawanto, D. A. (2014). Pengaruh Jumlah Sudu Terhadap Unjuk Kerja Dan Kavitasi Pompa Sentrifugal. Mekanika, 12(2), 78-83.

[6] Pratama, O., \& Siregar, I.H. (2019). Karakteristik Bilah Banyak Tipe Torque Flow Impeller. Jurnal Teknik Mesin, 7(1), 47-56.

[7] Wahkidur rohman, E. Siregar, I.H. (2015). Uji Eksperimen Pengaruh Jumlah Torque Flow Impeller Terhadap Kinerja Pompa Sentrifugal. Jurnal Teknik Mesin, 3(03), 145-151.

[8] Sarbu, I. (2016). A study of energy optimisation of urban water distribution systems using potential elements. Water, 8(12), 593.

[9] Dave, M. P., Mokariya, M. K., \& Patel, M. V. (2013). Energy conservation in centrifugal pump with variable frequency drive including SCADA, PLC and HMI. International Journal of Innovative Research in Science, Engineering and Technology, 2(5), 1461-1468.

[10] anonym., (2018). The Difference of Open, Semi-Open, Closed Impeller, https://www.muyuanpump.com/The-Difference-ofOpen-Semi-Open-Closed-Impeller-id6501366.html diakses tanggal 12 April 2020 